\title{
Effects of Functional Electrical Stimulation (FES) on the Temporal-spatial Gait Parameters and Activities of Daily Living in Hemiplegic Stroke Patients
}

\author{
Dong-Gun Oh, PT, PhD - Kyung-Tae Yoo, PT, Prof, PhD ${ }^{1 \dagger}$ \\ Department of Physical Therapy, Dongnam Health University, \\ ${ }^{1}$ Department of Physical Therapy, University of Namseoul
}

Received: June 6, 2021 / Revised: June 8, 2021 / Accepted: July 21, 2021

(c) 2021 J Korean Soc Phys Med

\section{| Abstract |}

PURPOSE: This study examined the effects of functional electrical stimulation (FES) on temporal-spatial gait and the activities of daily living in hemiplegic stroke patients.

METHODS: The subjects were 29 hemiplegic stroke patients $(57.7 \pm 10.3)$. The patients walked at a self-controlled speed in four states: (1) walking without FES (non-FES), (2) walking with FES on the gluteus medius in the stance phase (GM), (3) walking with FES on the common peroneal nerve and tibialis anterior in the swing phase (PT), (4) walking with both GM and PT. A GAITRite system, Timed-Functional Movements battery, and Timed UP and Go test were used to measure the variables.

RESULTS: Significant improvements were observed in all variables of the GM+PT, GM, and PT states compared to the non-FES state $(\mathrm{p}<.05)$. There were significant improvements in the GM+PT state compared to GM and PT states $(\mathrm{p}<.05)$.

†Corresponding Author: Kyung-Tae Yoo taeyoo88@nsu.ac.kr, https://orcid.org/0000-0001-7956-819X This is an Open Access article distributed under the terms of the Creative Commons Attribution Non-Commercial License (http://creativecommons.org/licenses/by-nc/3.0) which permits unrestricted non-commercial use, distribution, and reproduction in any medium, provided the original work is properly cited.
Moreover, significant improvements were noted in the single support time on the affected side, backward walking $10 \mathrm{ft}$, and side stepping $10 \mathrm{ft}$ on the affected side of the GM state compared to the PT state $(\mathrm{p}<.05)$. There were significant improvements in the stride length on the affected side and side stepping $10 \mathrm{ft}$ on the unaffected side of the PT state compared to the GM state $(\mathrm{p}<.05)$.

CONCLUSION: FES is effective in improving the temporal-spatial gait and activities of daily living in hemiplegic stroke patients.

Key Words: Activities of daily living, FES, Gait, Stroke

\section{Introduction}

An efficient gait is an important goal of rehabilitation in stroke patients [1]. They consume considerable energy while they walk. Abnormal kinematic and kinetic data are also shown [2], irregular muscle movements appear [3], and the gait asymmetry lasts for a long time despite the improvements in the motor selectivity, balance, and walking performance of the affected side [4]. Abnormal patterns make it difficult to engage in activities of daily living, reducing the individuals' independence, and limiting their social engagement [5-6]. The hip abductor is activated in the 
terminal swing and mid-stance during walking, but asymmetric weight shifting and bearing appear characteristically because the hip abductor's muscle activation is lacking in stroke patients [4]

FES is used to activate the function by stimulating the muscles and nerves of the paralyzed upper and lower extremities caused by a stroke [7]. Most studies on FES focus on preventing foot dropping and improving the function by stimulating the dorsiflexors in the swing phase to improve the gait ability of stroke patients [8-11]. On the other hand, there are limitations in improving the asymmetrical weight shifting and bearing of hemiplegic stroke patients by applying FES to the dorsiflexors [12].

A previous study attempted to apply FES to the hip abductors [12], and similar studies have been conducted since then. Most studies controlled the complex effects and compared them by applying FES simultaneously to the hip abductors and dorsiflexors or the hip abductors and knee extensors [13-14]. In addition, if FES is applied to the tibialis anterior to induce dorsiflexion [12-14], it can accelerate the abnormal gait pattern involving the tendency to step with an inversion of the lateral surface and the ankle joint in the initial stance [8].

Therefore, FES was applied to the common peroneal nerve and tibialis anterior to induce dorsiflexion and slight eversion [8-11]. This study examined the effects of FES on the gait by comparing four states, including a control, and the effects of FES on the daily living activities related to gait by applying FES to the hip abductors and dorsiflexors during walking in chronic stroke patients with hemiplegia.

\section{Methods}

\section{Participants}

The subjects were 29 hemiplegic stroke patients (57.7 $\pm 10.3)$ admitted to a rehabilitation hospital. The selection criteria included the following: (1) those diagnosed with hemiplegia due to a stroke more than six months earlier without other neurological diseases, (2) a Manual Muscle Test rating of $\mathrm{P}+$ or below of the hip abductors and dorsiflexors and available over the neutral in passive range of motion, (3) could independently walk more than $10 \mathrm{~m}$, (4) received more 24 scores on the Mini-Mental State Exam and could understand and follow the information the researcher indicated [15], and (5) no orthopedic diseases in the upper and lower extremities. Cardiac pacemaker wearers, those with skin lesions, who could not be treated due to spasticity within the last three months, and vestibular and cerebellar lesions or deaf- blindness were excluded $[8,16]$. The patients voluntarily signed a written informed consent form after being provided with an explanation of the experimental content. The Institutional Review Board of Namseoul University approved the study (NSU-160530-01). The participants were assigned randomly to a group using random number allocation methods on a computer.

\section{Experimental method}

FES (Microstim, Medel Gmbh Inc., Germany) was used for muscle contraction. The electrodes were attached to the gluteus medius (GM), common peroneal nerve and tibialis anterior (PT) of the affected side, and hip abduction, ankle dorsiflexion, and slight eversion were induced. For the GM, electrodes were placed on the line connecting the iliac crest and greater trochanter. For the common peroneal nerve, electrodes were placed on the point posterior and distal to the fibular head. For the TA, electrodes were placed on the point approximately $1 / 4$ to $1 / 3$ between the knee joint and the ankle joint in the lateral parallel direction of the medial shaft of the tibia [12].

Each subject performed gait using FES and a foot switch in the following four conditions: (1) gait without FES (non-FES state), (2) gait with applying FES to the GM in the stance phase (GM state), (3) gait with applying FES to the PT in the swing phase (PT state), and (4) gait with 
Table 1. General Characteristics of the Participants $(n=29)$

\begin{tabular}{cc}
\hline Characteristics & Values \\
\hline Sex (male/female) & $15 / 14$ \\
Age (years) & $57.7 \pm 10.3$ \\
Height (cm) & $162.5 \pm 7.3$ \\
Weight (kg) & $61.9 \pm 10.4$ \\
Post-stroke duration (months) & $26.1 \pm 13.7$ \\
Mini-Mental State Examination & $27.8 \pm 1.7$ \\
Etiology (ischemic/hemorrhage) & $17 / 12$ \\
Paretic side (left/right) & $14 / 15$ \\
\hline
\end{tabular}

Expressed as Mean $\pm \mathrm{SD}$

applying FES to the GM in the stance phase and the PT in the swing phase (GM+PT state). The intensity of FES was controlled in the range at which the subjects felt no pain. In the GM state, the subjects were allowed to engage in $30-35^{\circ}$ of hip abduction. In the PT state, the subjects performed dorsiflexion $10^{\circ}$ with slight eversion [12]. The wave of FES was an asymmetric biphasic wave with a frequency, pulse width, and ramp-up and ramp-down of $30 \mathrm{~Hz}, 30 \mu \mathrm{s}$, and 2 seconds, respectively. The foot switch was interconnected with FES. The GM was stimulated when the heel contacted the floor. The common peroneal nerve and TA were activated when the heel lifted off; it was set to move reciprocally using two switches in the $\mathrm{GM}+\mathrm{PT}$ state. Before the experiment, FES was applied to the subjects, and the attachment points and stimulus intensity were confirmed individually to implement the movements of the subjects.

\section{Data collection}

Before the measurements, the personal physical data, such as the height, weight, and leg length of the subjects, were collected. Table 1 lists the general characteristics of the participants. At least seven steps were recorded. The first and last steps were removed, and the mean value of the remaining steps was used for gait analysis to reduce the error between the steps. The lines were marked at 1 $\mathrm{m}$ intervals from the start to arrival spots of the electronic gait mat, and a gait length of $10.3 \mathrm{~m}$ was induced. The subjects walked at a comfortable gait speed as usual and maintained a constant speed until the end.

A GAITRite (GAITRite, CIR system Inc., USA) was used to analyze the temporal and spatial elements of the gait. The GAITRite consists of an electronic gait mat with a length and width of $8.3 \mathrm{~m}$ and $.89 \mathrm{~m}$, respectively, and programs collected information about many variables when walking. In this study, the following temporal gait elements were obtained through this test: step time on the affected side (s), step time on the unaffected side (s), gait velocity $(\mathrm{cm} / \mathrm{s})$, cadence(step/min), single support time on the affected side (\%), single support time on the unaffected side (\%), double support time on the affected side (\%), double support time on the unaffected side (\%), and spatial elements (stride length on the affected side $(\mathrm{cm})$ and stride length on the unaffected side $(\mathrm{cm})$.

The Timed-Functional Movements (TFMs) battery and Timed Up \& Go(s) (TUG) were used to measure the subjects' activities of daily living and balance ability. A professional neurological physiotherapist who was blind to the study and had five years of clinical experience measured the TFMs and TUG. The TFMs and TUG showed very high reliability as a method to evaluate the movement and balance abilities. In this study, six items out of 11 items on the TFMs and TUG related to gait were performed: ambulation forward $20 \mathrm{ft}$, backward walking $10 \mathrm{ft}$, side stepping $10 \mathrm{ft}$ on the affected side (s), side stepping $10 \mathrm{ft}$ on the unaffected side (s), walking up four steps on stairs, and walking down four steps (s) [17-18]. For four items (ambulation forward 20ft, backward walking $10 \mathrm{ft}$, sidestepping $10 \mathrm{ft}$ on the affected side, and sidestepping $10 \mathrm{ft}$ on the unaffected side), the distance was measured, and the time from the start before the starting line and to the end when both feet of the subjects passed the end line were recorded. For two items (walking up four steps and walking down four steps), the time when the subjects 
Table 2. Temporal-spatial Gait Parameters under the Four States

\begin{tabular}{lccccc}
\hline \multicolumn{1}{c}{ Variables } & Non-FES & GM & PT & GM+PT & F \\
\hline Step time in affected side (s) & $.97 \pm .34^{\text {bcd }}$ & $.90 \pm .30^{\mathrm{a}}$ & $.89 \pm .32^{\mathrm{a}}$ & $.85 \pm .28^{\mathrm{abc}}$ & $39.239^{*}$ \\
Step time in unaffected side (s) & $1.03 \pm .40^{\mathrm{bcd}}$ & $.94 \pm .36^{\mathrm{a}}$ & $.95 \pm .34^{\mathrm{a}}$ & $.92 \pm .34^{\mathrm{a}}$ & $43.937^{*}$ \\
Gait velocity $(\mathrm{cm} / \mathrm{s})$ & $34.62 \pm 17.17^{\mathrm{bcd}}$ & $38.63 \pm 18.27^{\mathrm{a}}$ & $39.36 \pm 18.33^{\mathrm{a}}$ & $44.16 \pm 20.44^{\mathrm{abc}}$ & $74.777^{*}$ \\
Cadence (step/min) & $67.63 \pm 16.45^{\mathrm{d}}$ & $72.70 \pm 17.14$ & $73.48 \pm 17.36$ & $78.38 \pm 16.63^{\mathrm{abc}}$ & $105.797^{*}$ \\
Single support time in affected side (\%) & $24.06 \pm 5.69^{\mathrm{bcd}}$ & $27.77 \pm 6.89^{\mathrm{ac}}$ & $26.12 \pm 6.03^{\mathrm{a}}$ & $29.73 \pm 6.37^{\mathrm{abc}}$ & $127.447^{*}$ \\
Single support time in unaffected side (\%) & $32.89 \pm 5.43^{\mathrm{bcd}}$ & $33.75 \pm 5.89^{\mathrm{a}}$ & $34.58 \pm 5.26^{\mathrm{a}}$ & $33.98 \pm 5.36^{\mathrm{a}}$ & $9.662^{*}$ \\
Double support time in affected side (\%) & $45.91 \pm 7.66^{\mathrm{bcd}}$ & $42.01 \pm 8.88^{\mathrm{a}}$ & $43.37 \pm 8.47^{\mathrm{a}}$ & $40.02 \pm 8.25^{\mathrm{abc}}$ & $40.189^{*}$ \\
Double support time in unaffected side (\%) & $45.37 \pm 7.60^{\mathrm{bcd}}$ & $42.57 \pm 8.87^{\mathrm{a}}$ & $43.07 \pm 8.93^{\mathrm{a}}$ & $41.10 \pm 8.68^{\mathrm{abc}}$ & $26.229^{*}$ \\
Stride length in affected side (cm) & $54.33 \pm 19.53^{\mathrm{bcd}}$ & $57.00 \pm 19.49^{\mathrm{a}}$ & $58.56 \pm 19.2^{\mathrm{ab}}$ & $62.48 \pm 20.40^{\mathrm{abc}}$ & $121.161^{*}$ \\
Stride length in unaffected side (cm) & $54.41 \pm 19.81^{\mathrm{bcd}}$ & $59.07 \pm 19.27^{\mathrm{a}}$ & $58.27 \pm 19.39^{\mathrm{a}}$ & $62.95 \pm 20.43^{\mathrm{abc}}$ & $85.982^{*}$ \\
\hline
\end{tabular}

Expressed as Mean \pm SD. Abbreviations: Non-FES = gait without FES state; GM = gait with FES stimulation on gluteus medius state; PT = gait with FES stimulation on the common peroneal nerve and tibialis anterior state; GM + PT = gait with FES stimulation on the gluteus medius and common peroneal nerve and tibialis anterior state.

${ }^{*} \mathrm{p}<.05$; a: significantly different from the Non-FES state; b: significantly different from the GM state; c: significantly different from the PT state; d: significantly different from the GM+PT state.

Adjustment of multiple comparisons: Bonferroni.

started walking up (or down) the stairs to the end when both feet reached the fourth step was recorded [11]. In the TUG, the time from the start with sitting in a chair with an armrest and height of approximately $46 \mathrm{~cm}$ and round the makers from $3 \mathrm{~m}$ away until return and sitting in the chair again was recorded [18]. The subjects were allowed to walk at a controlled speed by themselves. All tests were analyzed by calculating the mean value by carrying out each activity three times to measure the temporal and spatial elements and the activities of daily living.

\section{Statistical Analysis}

All data obtained were analyzed by SPSS PC + for Windows (version 18.0). The mean and standard deviations were calculated to present the descriptive statistics of the dependent variables. Repeated measures one-way ANOVA was used to examine the effects of the FES state (Non-FES, GM, PT, and GM+PT state), temporal and spatial elements, and activities of daily living. If statistically significant differences were shown, a Bonferroni's test was used for multiple comparisons. The statistical significance level was $a=.05$.

\section{Results}

\section{Temporal-spatial Gait Parameters}

Table 2 lists the changes in the temporal-spatial gait parameters according to the four states. In the GM+PT state, there were significant improvements in all parameters compared to the non-FES state $(p<.05)$. Significant differences were noted in the parameters except for the step time on the unaffected side and the single support time on the unaffected side compared to the GM and the PT state $(\mathrm{p}<.05)$. There were significant improvements in all parameters in the GM and the PT states compared to the non-FES state $(p<.05)$. In the GM state, there was a significant improvement in the single support time on the affected side compared to the PT state $(\mathrm{p}<.05)$. In the PT state, significant improvement in the stride length 
Table 3. Ability of Daily Living Parameters under the Four States

\begin{tabular}{lccccc}
\hline \multicolumn{1}{c}{ Variables } & Non-FES & GM & PT & GM+PT & F \\
\hline Ambulation forward 20ft (s) & $21.60 \pm 10.62^{\text {bcd }}$ & $18.39 \pm 8.89^{\mathrm{a}}$ & $17.92 \pm 8.72^{\mathrm{a}}$ & $15.25 \pm 7.07^{\mathrm{abc}}$ & $59.717^{*}$ \\
Backward walk 10ft (s) & $32.78 \pm 21.07^{\mathrm{bcd}}$ & $24.03 \pm 13.22^{\mathrm{ac}}$ & $25.49 \pm 13.51^{\mathrm{a}}$ & $21.48 \pm 11.76^{\mathrm{abc}}$ & $21.783^{*}$ \\
Side step 10ft in affected side (s) & $40.65 \pm 24.62^{\mathrm{bcd}}$ & $28.34 \pm 15.14^{\mathrm{ac}}$ & $30.53 \pm 16.49^{\mathrm{a}}$ & $25.35 \pm 14.23^{\mathrm{abc}}$ & $21.710^{*}$ \\
Side step 10ft in unaffected side (s) & $32.36 \pm 15.04^{\mathrm{bcd}}$ & $25.88 \pm 12.89^{\mathrm{a}}$ & $24.59 \pm 12.31^{\mathrm{ab}}$ & $21.78 \pm 11.47^{\mathrm{abc}}$ & $64.958^{*}$ \\
Stairs up 4 steps (s) & $13.04 \pm 4.24^{\mathrm{bcd}}$ & $10.75 \pm 4.31^{\mathrm{a}}$ & $10.58 \pm 4.18^{\mathrm{a}}$ & $9.27 \pm 3.86^{\mathrm{abc}}$ & $62.233^{*}$ \\
Stairs down 4 steps (s) & $14.50 \pm 5.87^{\mathrm{bcd}}$ & $11.65 \pm 5.56^{\mathrm{a}}$ & $11.94 \pm 5.63^{\mathrm{a}}$ & $10.45 \pm 5.09^{\mathrm{a}}$ & $53.517^{*}$ \\
Timed up \& go (s) & $44.09 \pm 18.74^{\mathrm{bcd}}$ & $35.88 \pm 16.50^{\mathrm{a}}$ & $36.33 \pm 16.26^{\mathrm{a}}$ & $32.26 \pm 15.40^{\mathrm{abc}}$ & $71.191^{*}$ \\
\hline
\end{tabular}

Expressed as Mean \pm SD. Abbreviations: Non-FES = gait without FES state; GM = gait with FES stimulation on gluteus medius state; PT = gait with FES stimulation on the common peroneal nerve and tibialis anterior state; GM+PT = gait with FES stimulation on the gluteus medius and common peroneal nerve and tibialis anterior state.

${ }^{*}<.05$; a: significantly different from Non-FES state; b: significantly different from GM state; c: significantly different from PT state; d: significantly different from GM+PT state.

Adjustment of multiple comparisons: Bonferroni.

was noted on the affected side compared to the GM state $(\mathrm{p}<.05)$.

\section{Activities of Daily Living Parameters}

Table 3 shows the changes in the activities of daily living parameters according to four states. In the GM+PT state, significant improvements were noted in all parameters compared to the non-FES state $(p<.05)$. Significant differences were observed in the parameters except for walking down four steps in the GM and the PT state (p $<.05)$. In the GM and the PT state, there were significant improvements in all parameters compared to the non-FES state $(\mathrm{p}<.05)$. In the GM state, significant improvement was observed in backward walking $10 \mathrm{ft}$ and side stepping $10 \mathrm{ft}$ on the affected side compared to the PT state $(\mathrm{p}<$ $.05)$. In the PT state, significant improvement in side stepping $10 \mathrm{ft}$ on the unaffected side compared to the GM state was noted $(\mathrm{p}<.05)$.

\section{Discussion}

This study was examined the effects of FES by applying it to the hip abductors, dorsiflexors, and simultaneously to the hip abductors and dorsiflexors on the gait and activities of daily living. In this study, there were statistically significant differences in all states applying FES. The positive changes appeared in the general gait pattern of the patients, and the step time was improved.

A study reported improvements in the dorsiflexion and plantar flexion of the ankle joint contributed to the improved gait ability [19]. The present study identified a static correlation between the dorsiflexion and the step length and stride length. In the PT state, this study also found more significant improvements in the stride length on the affected side than the non-FES state and the GM state, suggesting that stimulation of the dorsiflexors would help the patient move relatively fast and quickly in the swing phase on the affected side and may be related to the improved cadence. A study attributed the improved step length on the affected side to an improved gait velocity [14]. The stability and step length on the affected side showed significant improvement because applying FES during walking results in effective movement of the joint. Applying FES to the dorsiflexors in the swing phase decreased the period of the swing phase, contributing to an improved gait cycle and gait velocity [14]. In addition, 
many studies reported that FES stimulation of the dorsiflexors and complex FES stimulus with other muscles effectively improves the gait velocity, cadence, and stride length [12-14]. These results concur with this study.

In general, the GM is a very important factor that affects the gait and recovery of hemiplegic stroke patients' postural stability because a deterioration of the GM affects the stability guarantee and hip joint during the stance phase, and the GM has an important role in improving the single-limb support [20-21]. Thus, there was a greater improvement in the single support time on the affected side in the GM state than the non-FES state and the PT state in this study. Applying FES to the GM appeared to hold the appropriate position of the hip joint and contributed to improved stability. Moreover, in the double support time, it brought positive changes compared to the non-FES state. For the GM state, there were significant improvements in the step time, gait velocity, and cadence, in addition to no significant difference in the GM and PM states. This suggests that the variables related to the gait speed, such as step time, gait velocity, and cadence, with the elements related to stability, can improve through independent FES of the gluteus medius, not the dorsiflexors.

A previous study identified an association between the gait symmetry and velocity, cadence, double support period, and stride length and reported that the improved asymmetry of hemiplegic stroke patients improves their gait significantly [12]. These results corresponded to the results of this study. The recovery of the affected gluteus medius strength improved the gait speed because of the improved weight bearing on the affected side and balance [22] Another study analyzed the effects of FES on the gait speed, gait cycle, and step length by dividing subjects into four states: non-FES, tibialis anterior, tibialis anterior and quadriceps, and both tibialis anterior and GM [14]. The results correspond to a portion of this study.

In this study, there were more significant improvements in the variables related to the activities of daily living in the GM+PT state than in the other states. Significant differences in the GM state and the PT state compare to the non-FES state were noted.

In the ambulation forward 20ft, the results obtained were the same as the gait velocity. The action of the GM might be effective in improving gait stability and gait speed. In the backward walking 10ft, there were significant differences in the GM state compared to the PT state because the subjects depended heavily on the muscle strength, the vestibular system, and proprioception to control the postural stability when they were walking backward because their vision was blocked. Furthermore, postural control for body stability plays an important role in the hip joint and ankle joint. The hip joint action was increased when the range of body sway was large [23]. Therefore, the anxiety due to a visual block increased the body sway, and the gluteus medius appears to play a more effective role on the hip joint. In the sidestepping $10 \mathrm{ft}$, there was a significant improvement in the GM state compared to the PT state. A significant difference was noted in the affected side of the PT state compared to the GM state. The GM action plays an essential role in maintaining the center of the body. Sidestepping is a difficult functional movement to perform by hemiplegic stroke patients compared to the general gait, like backward walking. The results of this study in the GM state suggest that mobility and stability had positive effects on sidestepping on the affected side because of the stimulus of the affected hip abduction, but hip adduction to follow the unaffected side was limited compared to the PT state in the side stepping $10 \mathrm{ft}$ on the unaffected side.

In walking up four steps, walking down four steps, and TUG, there were significant improvements in the GM and PT states compared to the non-FES state but no significant difference between the GM state and the PT state. A study reported significant improvement in the TUG posttreatment and at a two-week follow-up in their study applying FES to the dorsiflexors twice a day, five times 
a week for four weeks [10]. The results correspond to the results of the present study. In this study, the most significant changes were observed in the variables for the GM+PT state, except for step time on the unaffected side, the single support on the unaffected side, and walking up four steps compared to the other three states. FES contributed more to the synergistic effects of the gait variables suggested by the previous studies of the FES on gait cycle [12-14] and to the improved biomechanical parameters measured by the activities of daily living.

\section{Conclusion}

This study showed that hip abductor action alone was sufficient to improve the variables related to the gait velocity and gait speed, such as the step time and cadence. The synergistic effects of the dorsiflexors and hip abductors were reconfirmed. Furthermore, there were improvements in the variables of the temporal-spatial gait and the activities of daily living. Thus, it would be necessary to employ various aggressive methods of FES to achieve functional improvement of hemiplegic stroke patients in a clinical setting.

\section{Reference}

[1] Duncan PW, Sullivan KJ, Behrman AL, Azen SP, Wu SS, Nadeau SE, Dobkin BH, Rose DK, Tilson JK. Protocol for the Locomotor Experience Applied Post-stroke (LEAPS) trial: a randomized controlled trial. BMC Neorol, 2007;7(1):39.

[2] da Cunha-Filho IT, Henson H, Wankadia S, Wankadia S, Protas EJ. Reliability of measures of gait performance and oxygen consumption with stroke survivors. J Rehabil Res Dev. 2003;40(1):19-25.

[3] Mulroy S, Gronley J, Weiss W, Newsam C, Perry J. Use of cluster analysis for gait pattern classification of patients in the early and late recovery phases following stroke. Gait Posture. 2003;18(1):114-25.

[4] Patterson KK, Parafianowicz I, Danells CJ, Closson V, Verrier MC, Staines WR, et al. Gait asymmetry in community-ambulating stroke survivors. Arch Phys Med Rehabil. 2008;89(2):304-10.

[5] Perry J, Garrett M, Gronley JK, et al. Classification of walking handicap in the stroke population. Stroke. 1995, 26(6):982-9.

[6] Chemerinski E, Robinson RG, Kosier JT. Improved recovery in activities of daily living associated with remission of poststroke depression. Stroke. 2001;3(1)2: 113-7.

[7] van Swigchem R, Weerdesteyn V, van Duijnhoven HJ, den Boer J, Beems T, Geurts AC. Near-normal gait pattern with peroneal electrical stimulation as a neuroprosthesis in the chronic phase of stroke: a case report. Arch Phys Med Rehabil. 2011;92(2):320-4.

[8] Hausdorff JM, Ring H. Effects of a new radio frequency-controlled neuroprosthesis on gait symmetry and rhythmicity in patients with chronic hemiparesis. Am J Phys Med Rehabil. 2008;87(1):4-13.

[9] Everaert DG, Thompson AK, Chong SL, Stein RB. Does functional electrical stimulation for foot drop strengthen corticospinal connections?. Neurorehabil Neural Repair. 2010;24(2):168-77.

[10] Wang YH, Meng F, Zhang Y, Xu MY, Yue SW. Full-movement neuromuscular electrical stimulation improves plantar flexor spasticity and ankle active dorsiflexion in stroke patients: A randomized controlled study. Clin Rehabil. 2016;30(6):577-86.

[11] Ring H, Treger I, Gruendlinger L, Hausdorff JM. Neuroprosthesis for footdrop compared with an ankle-foot orthosis: effects on postural control during walking. J Stroke Cerebrovasc Dis. 2009;18(1):41-7.

[12] Kim JH, Chung Y, Kim Y, Hwang S. Functional electrical stimulation applied to gluteus medius and tibialis anterior corresponding gait cycle for stroke. Gait Posture. 2012;36(1):65-7. 
[13] Cho MK, Kim JH, Chung Y, Hwang S. Treadmill gait training combined with functional electrical stimulation on hip abductor and ankle dorsiflexor muscles for chronic hemiparesis. Gait Posture. 2015;42(1):73-8.

[14] Mun BM, Kim, TH, Lee JH, Lim JY, Seo DK, Lee DJ. Comparison of Gait Aspects According to FES Stimulation Position Applied to Stroke Patients. J Phys Ther Sci. 2014;26(4):563-6.

[15] Kang YW. A Normative Study of the Korean-Mini Mental State Examination(K-MMSE) in the Elderly. Kor J Psychol. Gen. 2006;25(2):1-12.

[16] Weerdesteyn V, de Niet M, van Duijnhoven HJ, Geurts AC. Falls in individuals with stroke. J Rehabil Res Dev. 2008;45(6):1195-213.

[17] Rehm-Gelim SL, Light KE, Freund JE. Reliability of Timed-Functional Movements for Clinical Assessment of a Frail Elderly Population. Phys Occup Ther Geriatr. 1997;15(1):1-19.

[18] Podsiadlo D, Richardson S: The timed "Up \& Go". a test of basic functional mobility for frail elderly persons.
J Am Geriatr Soc. 1991;39(2):142-8.

[19] Lin PY, Yang YR, Cheng SJ, Wang RY. The relation between ankle impairments and gait velocity and symmetry in people with stroke. Arch Phys Med Rehabil. 2006;87(4):562-8.

[20] Powers CM. The influence of altered lower-extremity kinematics on patellofemoral joint dysfunction: a theoretical perspective. J Orthop Sports Phys Ther. 2003;33(11):639-46.

[21] Pandy MG, Andriacchi TP. Muscle and joint function in human locomotion. Annu Rev Biomed Eng. 2010; 12(1):401-33.

[22] Mercer VS, Chang SH, Williams CD, Noble K, Vance AW. Effects of an exercise program to increase hip abductor muscle strength and improve lateral stability following stroke: a single subject design. J Geriatr Phys Ther. 2009;32(2):50-9.

[23] Runge CF, Shupert CL, Horak FB, Zajac FE. Ankle and hip postural strategies defined by joint torques. Gait Posture. 1999;10(2):161-70. 